\title{
Challenges of randomized controlled trial design in plastic surgery
}

\author{
Aladdin H Hassanein MD MMSc, Fernando A Herrera MD, Omar Hassanein BS
}

\begin{abstract}
AH Hassanein, FA Herrera, O Hassanein. Challenges of randomized controlled trial design in plastic surgery. Can J Plast Surg 2011;19(3):e28-e29.

Randomized controlled trials are the gold standard of evidence-based medicine. In the field of plastic surgery, designing these studies is much more challenging than in pharmaceutical medicine. Randomized trials in plastic surgery encompass several road blocks including problems shared with other surgical trials: equipoise, high cost, placebo issues and learning curves following the establishment of a novel approach. In addition, plastic surgery has more subjective outcomes, thus making study design even more difficult in assessing the end result.
\end{abstract}

Key Words: Controlled; Design; Plastic; Randomized; Surgery; Trials

\section{Les défis de la conception d'essais aléatoires et contrôlés en chirurgie plastique}

Les essais aléatoires et contrôlés constituent la référence en médecine probante. Dans le domaine de la chirurgie plastique, la conception de telles études est plus compliquée qu'en médecine pharmaceutique. En effet, en chirurgie plastique, les essais aléatoires englobent plusieurs obstacles, y compris des problèmes observés dans d'autres essais chirurgicaux : la pondération, les coûts élevés, le problème des placebos et les courbes d'apprentissage après la mise en œuvre d'une démarche novatrice. En outre, les résultats de la chirurgie plastique sont plus subjectifs, ce qui rend la conception des études encore plus difficile sur le plan de l'évaluation des résultats.

the surgeon. In type III trials (an operation versus medical treatment), recruitment is difficult because patient equipoise is difficult to establish (6). Patients may either believe that a more invasive operation constitutes greater efficacy than a simple medication or would prefer to avoid an operation that is not established as the preferred therapy. Both scenarios lead to difficulty in finding patients who are willing to consent to this type of study design. Modifications to classic randomization are often required and are subject to criticism.

Randomized controlled trials comparing medical therapies often use placebos as the control arm to factor out confounders, and give a clearer picture regarding efficacy of the treatment. It is easier to establish statistical significance by comparing the therapy with placebo, which has no chemical benefit. A surgical placebo equivalent has historically been 'sham surgery', whereby the patient receives anesthesia, the incision and the operation, with the therapeutic portion omitted. The patient is subjected to the surgical risks without the potential benefit. Equipoise is in question: undergoing an entire surgery except for the therapeutic intervention is clearly not the best treatment (8). The goal of the trial is to potentially prevent future patients from undergoing risks of a nonbeneficial operation. In the past, trials using sham surgery have been successfully used to stop unnecessary operations from being performed such as ligation of the internal mammary artery for the treatment of myocardial ischemia (9). The American Medical Association states that surgical placebos should only be used when no other trial design will yield acceptable data (10).

Conversely, in a medical trial, the traditional placebo pill does not share the same risks as the drug therapy. The medical intervention is a discrete unit. The experimental arm unquestionably gets a pill with the chemical under investigation, while the control arm gets a pill without the chemical. In surgery, the therapy (the operation) is not uniform; each operation varies including the same type of operation performed by the same surgeon. Technical proficiency for a new operation is subject to a learning curve, even in the hands of the most skilled surgeons. Technical precision and efficiency is gained incrementally as the number of procedures is repeated, until the tapering of the learning curve at the 'proficiency level'. Small adjustments in technique are 
unlikely to be significantly detected in outcome. Thus, there is a fine line between technique development and research (11). When a novel procedure is first being implemented after development, the number of procedures needed to reach proficiency varies according to technique; this is reflected in the outcome.

The conclusions drawn from a randomized surgical trial on a novel technique do not translate universally to practice. Surgeons who subsequently start to use the technique are not likely to obtain the same end result as the investigators because they are not yet 'proficient' in the operation. The laparoscopic cholecystectomy was first introduced in 1989. An analysis of the large prospective trial published in the New England Journal of Medicine in 1991 - that helped propel laparoscopic cholecystectomy into widespread acceptance - showed that from the 8839 cases performed by 55 surgeons in the trial, $90 \%$ of bile duct injuries occurred in the individual surgeon's first 30 cases (12). Therefore, even while the justification for performing a new procedure may be evidence based, the evidence would not necessarily apply until the proficiency level is reached.

Plastic surgery trials are subjected to challenges that apply to any randomized surgical trial, along with additional challenges. The learning curve often has three phases: an initial decrease in complications, a subsequent decrease in variance in operation time and, finally, a

\section{REFERENCES}

1. Filho JV, Castro AA, Veiga DF, et al. Quality of reports of randomized clinical trials in plastic surgery. Plast Reconstr Surg 2005;155:320-3.

2. Momeni A, Becker A, Antes G, et al. Evidence-based plastic surgery: Controlled trials in three plastic surgical journals (1990 to 2005). Ann Plast Surg 2009;62:293-9.

3. Taghinia AH, Liao EC, May JW Jr. Randomized controlled trials in plastic surgery: A 20 year review of reporting standards, methodologic quality, and impact. Plast Reconstr Surg 2008;122:1253-64.

4. Gelijns AC, Ascheim DD, Parides MK, et al. Randomized trials in surgery. Surgery 2009;145:581-7.

5. Chang EY, Pannucci CJ, Wilkins EG. Quality of clinical studies in aesthetic surgery journals: A 10-year review. Aesthet Surg J 2009;29:144-7.

6. McCulloch P, Taylor I, Sasako M, et al. Randomised trials in surgery: Problems and possible solutions. BMJ 2002;324:1448-51.

7. Johnson N, Lilford RJ, Brazier W. At what level of collective equipoise does a clinical trial become ethical? J Med Ethics 1991;17:30-4.

8. Tenery R, Rakatansky H, Riddick FA, et al. Surgical "placebo" controls. Ann Surg 2002;235:303-7. decrease in total operation time (13). This may be due to relatively less dependence on technology in plastic surgery operations compared with other specialties; equipment setup and use includes a fixed amount of time that is difficult to minimize. Therefore, the outcome of a randomized plastic surgery trial would not hold true when first put into widespread practice.

Another unique problem of randomized trials in plastic surgery is the difficulty in the measurement of the outcome variable. Most plastic surgery operations are intended to improve quality of life or restore function. There are limited valid benefit assessment tools of those operations because they are more subjective and more difficult to quantify (14). These 'soft outcomes' are not as black and white as mortality or five-year survival rates. Subsequently, most plastic surgeons have traditionally relied less on quantitative evidence and more on experience (15).

\section{CONCLUSION}

Randomized trials in plastic surgery encompass several road blocks including problems shared with other surgical trials: equipoise, high cost, placebo issue and learning curve following the establishment of a novel approach. In addition, plastic surgery trials have more subjective outcomes, making study design even more difficult in assessing the outcomes.

9. Cobb LA, Thomas GI, Dillard DH, et al. An evaluation of internal-mammary-artery ligation by double-blind technique. N Engl J Med 1959;260:1115-8.

10. Council on ethical, judicial affairs, American Medical Association. Opinion 2.076: Surgical "placebo" controls. In: The American Medical Association's Council on Ethical and Judicial Affairs. Code of Medical Ethics. Chicago: American Medical Association, 2000.

11. Margo CE. When is surgery research? Towards an operational definition of human research. J Med Ethics 2001;27:40-3.

12. Moore MJ, Bennett CL. The learning curve for laparoscopic cholecystectomy. The Southern Surgeons Club. Am J Surg 1995; 170:55-9.

13. Carty MJ, Chan R, Huckman R, et al. A detailed analysis of the reduction mammaplasty learning curve: A statistical process model for approaching surgical performance improvement. Plast Reconstr Surg 2009;124:706-14.

14. Khan AA, Murthy AS, Ali N. Randomized controlled trials in plastic surgery. Plast Reconstr Surg 2006;117:2080-1.

15. MorainWD. Get random. Ann Plast Surg 1995;34:669-70 